\title{
Autocratic, Democratic, Transformational and Charismatic Leadership Styles and Contingency of Different Performance Outcomes in SMEs
}

\author{
Dr. Zafar Iqbal \\ Professor, FAST School of Management \\ National University of Computer \& Emerging Sciences, Lahore Campus \\ zafar.iqbal@nu.edu.pk \\ Dr. Amna Niazi \\ Assistant Professor, Humanities and Social Sciences Department \\ University of Engineering and Technology, Lahore, Pakistan \\ amna.niazi@uet.edu.pk \\ Dr. Hamid Hassan \\ Professor \& Director, National University of Computer \& Emerging Sciences \\ FAST-NU, Lahore \\ hamid.hassan@nu.edu.pk
}

\begin{abstract}
We analyze four different leadership styles from multiple dimensions to find out the suitability of these styles for the leaders working in Pakistani small and medium enterprises (SMEs). Theoretically, it is an additional perspective in the debate on effectiveness of different leadership styles in different environments for different purposes. It starts with analyzing contemporary theories of leadership and their derivative styles. Next, it discusses the major aspects of organizational environment coming from the broader culture of a country. Subsequently, it tries to provide a more balanced view in the debate on cause and effect of leadership styles and their effectiveness in specific organizational culture. In the empirical analyses the study analyzes the productivity, acceptance and sustainable success of different leadership styles in the organizations working in Pakistan. The data is collected both from business leaders and their relevant followers. The findings of study explains that outputs when measured in terms quantity shows better results for autocratic leadership style while democratic leadership style give better results when measured in terms of quality. Similarly, willingness of followers to continue and their inspirations beyond the formal organizational structure are higher for charismatic and participative leadership styles.
\end{abstract}

Key words: leadership styles, effectiveness, productivity, organizational culture, willingness of followers, inspirations

\section{Introduction:}

Leadership role for a healthier firm performance is widely advocated in the research literature (Day \& Lord, 1988; Bass, 1990; Newman, 1993; Conger et al., 2000; Kaiser et al., 2008). In the current dynamic business environment a powerful leadership style can be a competitive 
advantage especially for small and medium enterprises (SME) (Isenberg, 1987; Bird, 1992; Vecchio, 2003; Hunter et al., 2007). SMEs are at disadvantage vis-à-vis big companies in several aspects (Eden et al., 1997). For instance, large firms may have an edge over SMEs in terms of larger size that can absorb financial shocks, economies of scale in structure that can bring about cost efficiency and capacity to retain better human recourses (Meredith, 1987; Santarelli \& Sterlacchini, 1990; Eden et al., 1997; Lefebvre et al., 1991). To counter these disadvantages against the bigger rivals it is advisable that SMEs should aim for smaller niches in the target market (Thompson \& Strickland, 1996; Ghemawat, 1991). A strategy of harvesting the mass market and leaving minor niches for smaller firms is referred to as intentional irrationality of bigger firms to keep focus on bulk margins (Ghemawat, 1991). However, with the localization of large multinationals through long experiences and increases in competition this strategy has not remained a viable solution for SMEs any more (Khai et. al. 1999). It can be said that probably the 'irrationality' of large firms is likely to be converted into rationality with the gain of experience, learning of local markets and increase in competition. It is therefore advisable for SMEs to adopt a more proactive approach rather than a passive strategy of relying on short term irrationality of large rivals (Buckley, 1989; Taco \& Someren, 1995). To offset the disadvantage of small structure of SMEs it would be viable to find advantages in the same citrus paribus.

One of the advantage of small structure of SMEs is the possibility of creating highly coherence among the members. In this context effective leadership styles can play a vital role in influencing the members for high level of motivation and improve performance. Small structure and limited number of members make it possible to physically see each other and get influences directly from the leaders in such organizations. Thus synchronization of employees towards specific targets can create a huge competitive edge for the company (Cannella \& Monroe, 1997; Carpenter \& Fredrickson, 2001). Direct contact of all employees with the leader helps to bring about a bigger margin of capitalizing the effective leadership style (Mintzberg, 1979; Yukl, 2006). While appropriate leadership style can be critical for the success of a firm (Yukl 2008) its role is far more powerful for the SMEs. This is because small firms have a lot of influence coming from the owners running these firms (Susan \& Fred, 2006). In large structure of these firms, several layers of management separate leaders from lower level employees scattered diversely. In SMEs however, there is direct and close influence of top leaders on all the followers (Eggers \& Smilor 1996; Stewart 2009).

A firm may pursue different targets in a given situation, depending upon its internal and external environment in a competitive market (Porter, 1980; Weinrauch et al., 1991). A small firm may feel this to a greater extend due to its dynamic needs and intense pressure from bigger competitors. Hence it is likely that SMEs may need to emphasize on different type of outcomes from employees under given circumstances. At times an SME may need to focus on producing large quantity while under different circumstances it may need to look for better quality. Similarly, there can be an emphasis on retaining employees due to the nature of product and skills required. Yet under a quickly expanding and volatile environment, the firm may need to focus on motivation of employees to help the firm and perform beyond the formal requirements of their jobs. This paper explores the suitability of different leadership styles to cater these diversified requirements under different circumstances for SMEs.

The four leadership style are selected after a broad literature review of discussion on leadership styles available in past research. Large number of leadership styles are summed up into four representative leadership styles with the help of three board schools of thought in leadership 
literature i.e., Trait theories, behavioral theories and contingency theories (Yukl, 2006: Yukl 2008). The selected leadership styles include charismatic leadership, autocratic leadership, democratic leadership and transformational leadership. Among these four selected leadership styles, the charismatic style represent the trait theories, while autocratic and democratic styles are derivative of behavioral theories. The transformational style is relevant to contingency theories. It is proposed that suitability of different leadership styles may depend upon the need of and SME to emphasize a certain focus under given circumstances. These focuses may include cost cutting, looking for creativity, increasing motivation \& retention, teamwork or looking for coordination \& empathy among workers. At times a firm looks for several of these in an order of priority. These requirements are simplified into four broad set of priorities that SMEs may look for in order to find their suitability with four different leadership styles in the empirical analyses. First set of requirements that include better productivity, cost cutting and emphasize on economies of scale is a broad goal of termed 'better quantity of output.' The requirements of focusing on specific needs of customers, bringing in creativity, quality and excellence are grouped as 'improvement in quality of output'. A focus to get benefit of specific human capital with the help of retention of valuable resources and organizational commitment is identified as 'willingness of employees to continue with the leader'. An effort to bring in teamwork, mutual empathy and group cohesiveness is categorized as 'inspirations of followers beyond the formal organizational structure.'

It is proposed that charismatic leadership style may be more suitable when focus of firm is on set of requirements relevant to 'willingness of followers to continue' and 'inspirations of followers beyond organizational structure.' A focus on 'better quantity of output' may get served through autocratic leadership style. The democratic leadership style may help in achieving the set of requirements relevant to 'improvement in quality of output.'

The remainder of the paper is organized as following. Section two presents the literature review and special challenges faced by SMEs. The expected effectiveness of different leadership style under these challenges are also discussed in this section. It explains three different schools of thought in leadership theory and derive four major-representative leadership style from these theories to be used in the study. Proposed model is presented in section three. Section four explains the data and sample. Section five elaborates the empirical analyses. Results and findings of study are discussed in section six. Section seven and eight present the conclusion and limitations of study respectively.

\section{Literature Review:}

\subsection{SMEs and their Challenges}

In a competitive market survival and success is a critical challenge for SMEs (Kao, 1981). This is because when compared to larger firms, SMEs generally operate with small span of resources (Eden et al., 1997). The benefits of economies of scale in production and ability to sustain against short term loses is also limited in SMEs (Weinrauch et al., 1991). Past research on SMEs have discussed problems of SMEs relevant with their small size, operational flexibility and inadequate financial backup against short term shocks (Moore \& Justin, 1987; Cook, 1992; Scarborough \& Thomas, 1991). Thus past literature mainly advocate a defensive format for SMEs (Bhide, 1994). It is generally recommended that SMEs may avoid a direct competition with the large firms and try to capture small un-attended market niches left over by the larger counterparts (Ghemawat, 1991; Lefebvre \& Lefebvre, 1993; Thompson \& Strickland, 1996). There has been a wide acceptance of this logic and it is probably because of this reason that less attention is given on 
developing a direct competitive strategy for SMEs in a competitive market of large firms (Davis et al., 1985; Jones, 1991; Tarkenton \& Joesph, 1991). It is said that large firms intentionally leave some of the small pockets while keep focusing on larger positions Ghemawat (1991). This is generally termed as intentional 'irrationality' of large firms and an opportunity for SMEs to settle in those small niches to avoid any direct competition with the large counterparts.

However there can be several limitations that can prevent an SME to fully adopt such a strategy. Some of these may include special nature of product that requires large firms to go for a more differentiation strategy, easy approach to customers or long-term existence of large firms in the market that can make it possible to avoid irrationality explained by Ghemawat (1991). Other possibilities include aggressive strategy of large firms under tough competitions and small profit margins. It is therefore plausible to focus on potential edges of SMEs to help device a better survival and profitability strategy for them. Efficient organization of small structure and role of leadership under such conditions is one of the key area where SMEs can have an edge over bigger rivals (Tichy \& Devanna, 1986; Conger, 1991; Jensen \& Luthans, 2006). Similarly SMEs present a case where organizational structure is less formal due to small size, less rigid without bureaucratic hurdles as compared to larger firms. In this context, it is easy to synchronize and bring in enormous improvement in the efficiency. An effective leadership can play crucial role to make this happen. A powerful leadership style under such conditions can inspire, influence and charge employees for a performance that is beyond the formal bindings and requirements of organizational structure. This paper investigates the effective use of right leadership style to bring in above benefits in SMEs.

\subsection{Special Nature of SMEs vis-à-vis Large Firms}

Reviewed literature in this section may have implications both for large and small firms. However as discussed earlier it is more critical as well as easy for SMEs to utilize this potential because of small structure that requires less effort to adopt it. This is because potential of synchronization of efforts is far easier in a small structure vis-à-vis large companies. The power of synergy can bring in huge margins of improvement in productivity, efficiency, creativeness and teamwork. A perfect synchronization can potentially bring in a massive improvement in efficiency that is fairly beyond the normal horizon of performance and effective leadership is probably the only factor that can produce such a synchronization. History is full of such examples where great leaders accomplished otherwise impossible tasks with the power of synchronization under tough conditions and limited resources. There might be a debate on possibility of achieving an ideal synchronization, it is at least established that near ideal was practiced in several of past examples.

As discussed earlier the effective leadership style and margin of improvement is applicable to all small and big organizations, however the SMEs are better candidates for such improvement with their small structure and special nature.

For instance, in large organizations several layers of management divide leaders and followers, while in SMEs there is generally direct contact of leaders with the employees. This makes it possible to easily channelize the unswerving influence of leadership towards the followers. A direct and personal contact of leaders with the follower also provide a chance to influence them beyond hierarchical and structural boundaries. Low formulization in small structure also helps in the change process of shifting to better level of performance without bureaucratic hurdles typically found in large systems. Similarly, grievance handling process can be much easily 
facilitated and feedback from followers can be obtained directly in a small structure. This makes SMEs more appropriate to capitalize the influence of appropriate leadership style.

SMEs are generally incorporated and owned by owners themselves who lead them. This shows that conflict of interest with the organization is eventually almost zero for those who lead them. However, different SMEs may have different strategies and performance priorities which may match with different leadership styles. In this paper we try to propose appropriate leadership styles for four different strategic preferences in SMEs that are discussed in the next section.

Despite plenty of discussion on these challenges that SMEs have to face, there have been much limited recommendations about the ways to cope with such problems. Literature on solving such problems of SMEs is too scanty. Applied research in this field generally suggests an avoiding approach to SMEs for survival in cut throat competition of businesses. Keeping in view this avoiding approach, defensive format of strategies is proposed for SME with focus on available market niches. Using this approach, SMEs can avoid being exposed to direct competition with the big rivals in the market. This approach however, has obvious disadvantages. For example, this approach may limit firms to exploit bigger margins of profitability and convert challenges into opportunities. Defensive approach on part of SMEs in smaller market niches give opportunity for bigger companies and multinationals to come in and push them out of the businesses. The avoiding approaches can therefore, only help in to survival for short term and that too missing to capitalize on chances of better margins. In order to benefit from better margins and maintain competitive edge in the long-term the SMEs should focus advantages of their small structure because in this case communication is much easier. Small structure helps in maintaining personal contacts with respective employees and motivating and influencing them for a common cause.

\subsection{Leadership Style and Strategic Priorities of SMEs}

Leadership is explained with respect to three different approaches in past literature i.e., trait theories, Behavioral theories and Contingency theories (Bass, 1999; Yukl, 2006). As evident from names, trait theories focus on personality traits to explain the leadership phenomenon while behavioral theories advocate sets of behaviors and level of involvement from followers to present different leaders (Judge \& Bono, 2000; Yukl 2008). Contingency theories, on the other hand, consider three factors to show an appropriate leadership style by the combination of leadership style, followers and the situation in which leadership is supposed to work (Yukl 2008). It is contingency approach that include both of the previous explanations of leaders and match it with different situations to suggest different leadership styles.

Theoretical work on leadership started with one of the initial efforts by Carlyle (1840) who presented that idea of Great man (later called great man theory). This idea explains leaders are born with noble characteristics and lead their groups through them. Herbert Spencer (1896) questioned the idea of Great men and argued that leaders are shaped by their environment to develop certain traits that help them to lead. Nevertheless, both advocates the traits as predictors of leadership. This school of thought remained popular during 1900s to explain leadership (Cowley, 1931). Eventually early studies could not reach a consensus on a common set of traits that can define leadership (Mann, 1959; McGregor, 1960). Research in this direction continued to differentiate leaders from followers on the basis of personality characteristics (Block, 1995; Judge et al., 2007). Specific traits relevant to leadership have been advocated in several past studies (i.e., Kinder et al., 1980; Judge, et al., 1999; Marcus et al., 2000; Rahn, 2000; Sullivan et al., 1990; Kirkpatrick \& Locke, 1991; Judge, et al., 2004). However, insufficiency of trait theories to explain leadership in the context of success remained the major problem (Jenkins, 1947; Mann, 
1959). Despite critiques empirical work on trait parading continues to date (Kickul \& Neuman, 2000; Judge et al., 2004; Mumford et al., 2007). House (1977) coined the term of charismatic leadership. This paper has selected this as one of the leadership style to be used in this study from trait paradigm. Later one several other studies also explored the charismatic leadership on the basis of personality characteristics of liveliness, attraction, personal lure and enthusiasm (House \& Howell, 1992; Conger \& Kanungo, 1994). Such leaders can sense the gap between current and the desired state of followers through effective communication and clear expression and that they influence them to achieve a shared objective (Leanne et al., 1991; Bass, 1990; House \& Howell, 1992). Charismatic style leaders can prove more powerful in SMEs because employees can directly talk, see and interact with the leaders/owners. Leaders having such style are not bound for the organizational structure to influence followers. Hence they can be useful in SMEs by uniting individual efforts through flexibility, spontaneity and vision of focusing on a common goal. These requirements can be categorized as "motivations of followers afar from organizational bindings and propose which can be better achieved through charismatic leadership style.

The second school of thought on leadership is present in the form of behavioral approaches of leadership. According to these theories, it is leader's behavior that determine their success in leadership (Yukl, 1989; Yukl, 2006). The behavior of leaders may vary in different situations (Blake \& Mouton, 1964). Empirical studies in this direction have explained that the behavioral aspects matter in success of leaders (Bass, 1990; Burke et al., 2006). These theories suggest two folded behaviors of leaders i.e., concern for task and concern for people (i.e., Stogdill, 1948; Stogdill, 1963). These behavioral approaches discussed by famous leadership studies of Ohio State University and Michigan State University in 1950s are commonly mentioned in the researches on leadership (Bass, 1990; Avolio et al., 2004; Bass \& Bass, 2008). In order to make our study in line with the studies by Ohio and Michigan State Universities, we chose Autocratic style to represent task oriented leaders and Democratic to represent people oriented behaviors of leaders. SMEs having limited span and narrow activity margins have focused tasks and people requirements. When there is requirement to contain cost and give greater output the task oriented style may be recommended work better. It is much plausible to recommend Autocratic style by leaders for better results for all these requirements. However, when we need our employees' to be creative, excellent in work and be participative, people oriented style can be preferred choice. It is therefore much plausible to recommend democratic style to represent people oriented style for better results against all these requirements.

Third line of theories about leadership that we explored in this study in relation to SMEs relates to contingency Approach of leadership. This line of theories considers an additional concern of followers and situation in the overall picture. This line of theories posits that leadership effectiveness depends a suitable fit between leadership behavior, situation and the composition of followers (Fiedler, 1967, 1970; Pearce \& Jr., 2002). Due to the focus of contingency theories of leadership on the different combination of leadership with given situations the term leadership styles was copied from this approach to other approaches. This line of theories stresses flexibility in leader's style that could adjust according to the situations and followers to be effective (Burns, 1978; Yukl, 2006). Contingency theories differ from others due to focus on the need for adjusting leadership style with the followers instead of bothering about traits or some permanent behaviors of leaders (Cogliser \& Schriesheim, 2000). 
Transformational style of leadership has been selected to represent contingency school of thought. We however, acknowledge that this selection to represent this type of style is relatively difficult because contingency theories only talk about between followers, situation and adopting the style accordingly. The selection of transformational style is an endeavor to express the fundamental idea of these theories i. e., followers central. Other plausible reason for selecting transformational style is the requirement of SMEs discussed earlier that imply to use this style. Considering the limited ability of SMEs to offer a long term contracts for employees and ensure employment security, transformational style may ensure to retain good employees. It is felt that retention of good employees is easily achievable through transformational style of leadership in SMEs. We therefore posit that followers will be more willing to stay with their transformational leaders.

\section{Study Model}

Our study model is supported by the literature review covered in preceding section. Apposite leadership is a significant factor for achievement of set goals by a firm (Conger, 1991; Tichy \& Devanna, 1986; Conger \& Kanungo, 1987). In case of SMEs it is proposed that appropriate leadership can help overcome critical resource limitations issue. We selected 4 styles of leadership and investigated their effectiveness for SMEs. These are include Charismatic leadership style from trait theories, Autocratic leadership style and Democratic leadership style from behavioral theories and transformational leadership style from contingency theories. Due to different needs of firms it is not be rational to measure effectiveness of leadership style in relation to one odd factor (Yukl, 2006). Therefore we investigated the positive impact of leadership style in relation to the diverse requirements of SMEs in different situations. Effectiveness of leadership styles may depend upon the objectives selected by the firms. Firm's preference for one objective over another will affect suitability of style of leadership in each situation. To this end, we have identified four strategic objectives that the SMEs may opt for. The choice of objectives depends upon different requirements of SMEs which include cost reduction, enabling employees to be creative, enhancing work motivation, longer tenure of good employees, promoting teamwork and capitalizing on the coordination and shared empathy between workers. Simplifying these requirements of SMEs we can propose four objectives that companies may aim at through the success appropriate leadership style. These are:

1) Quantitative advantage that represents cost reduction and improved productivity

2) Qualitative advantage that represents employees' creativity, excellence, imagination and motivation for work.

3) Employee retention to get advantage good human capital.

4) Inspiration of employees beyond the formal organizational structure to get advantage of teamwork, coordination, mutual, empathy, and enthusiasm.

Our hypotheses are related to four representative leadership styles discussed earlier and their effectiveness with respect to the strategic objectives that SMEs look for. Our hypotheses are:

1) Charismatic leadership style is positively correlated with inspirations of employees beyond the organizational structure.

2) Autocratic leadership style is positively correlated with better quantity of output.

3) Democratic leadership style is positively correlated with quality of work.

4) Transformational leadership style is positively correlated employees willingness to remain with the firm. 
It is well established that an effective leadership style contributes positively in the success of firms, but we will explore the most powerful impact of selected leadership styles. This means that a given leadership style can have constructive outputs in any or all four requirements. Nevertheless, it is proposed that it may show the strongest impact in one of the four requirements. The proposed highest output is presented through bold lines in the following figure.

Figur-1: Proposed Model

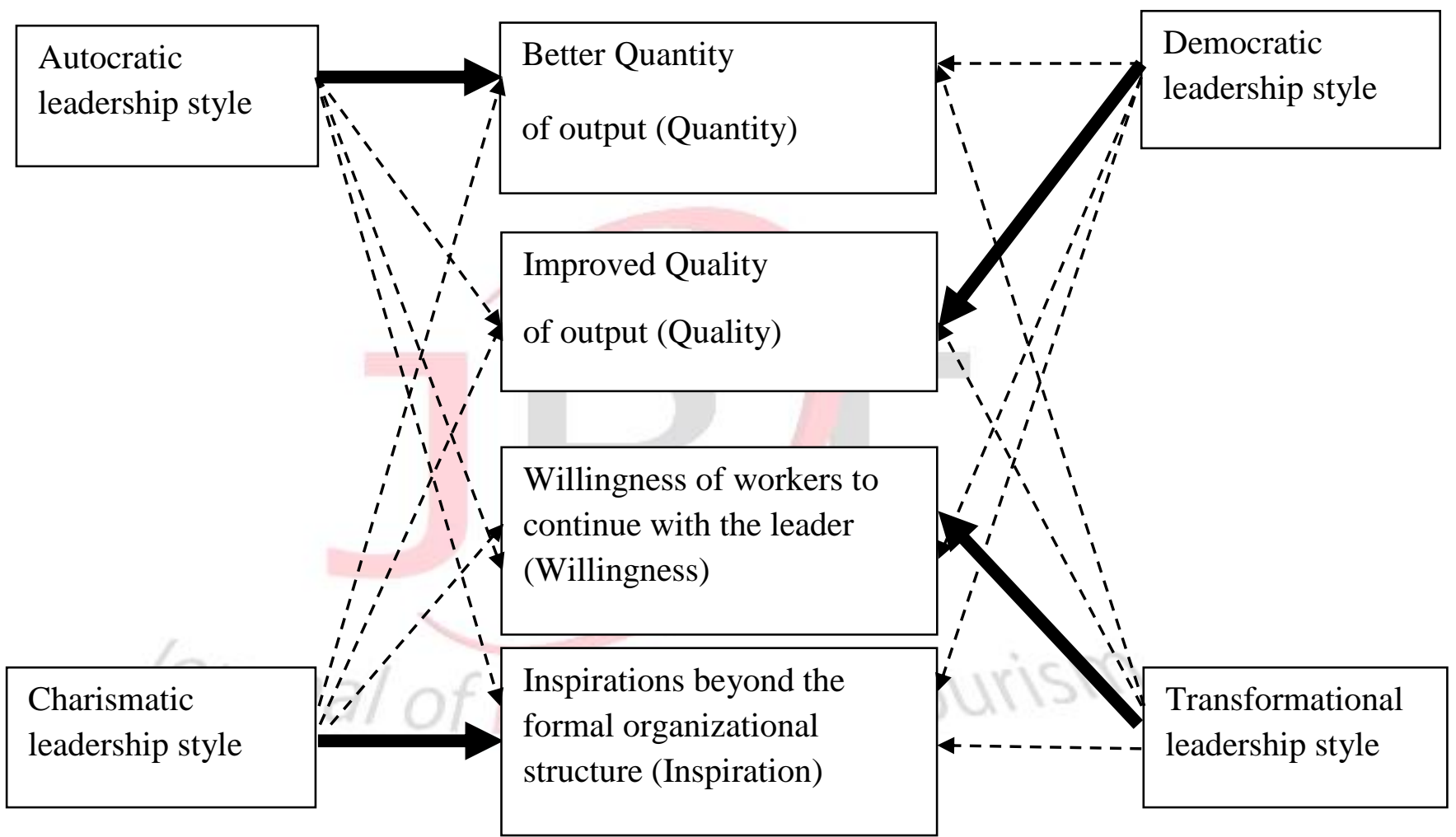

\section{Data and Sample}

Data was collected from SMEs located in Lahore, Pakistan. The sample comprises 90 leaders and their respective five followers working in these SMEs. Different surveys were used to collect data from leaders and their followers. Five point likert scale was used for the responses regarding leadership style and four proposed outputs. The questionnaire for leaders has twenty questions to assess leadership style of leaders. First five questions determine the directive aspiration, desire of more control and power orientation on part of the leaders. Score in these questions determines the leader's inclination towards authoritative style. Questions 6 through 10 are about creativity of followers, consensus, participation, and relationship building by leaders. Score of these questions shows democratic style of leadership. Questions 11 through 16 are about concern for followers, their training growth and rational thinking. Score of these questions shows the transformational style of leadership. Questions 11 through 16 are about leaders' parental attachment with the followers, establishment of a hope in them, effective communication and boosting their 
confidence. Score of these questions shows transformational leadership style. Although these leadership styles are not mutually exclusive, the survey tool can help determine the leaning of leaders towards one of the four styles.

Similarly, followers' questionnaire shows the effectiveness of leaders, on the basis of opinion of followers about four selected objectives of SMEs. This questionnaire comprises of twenty questions to measure quality of output, quantity of output, willingness to remain with the leader and inspirations beyond the binding of organizations. Score in case of four basic objectives shows the effectiveness of each leadership style related to that objective.

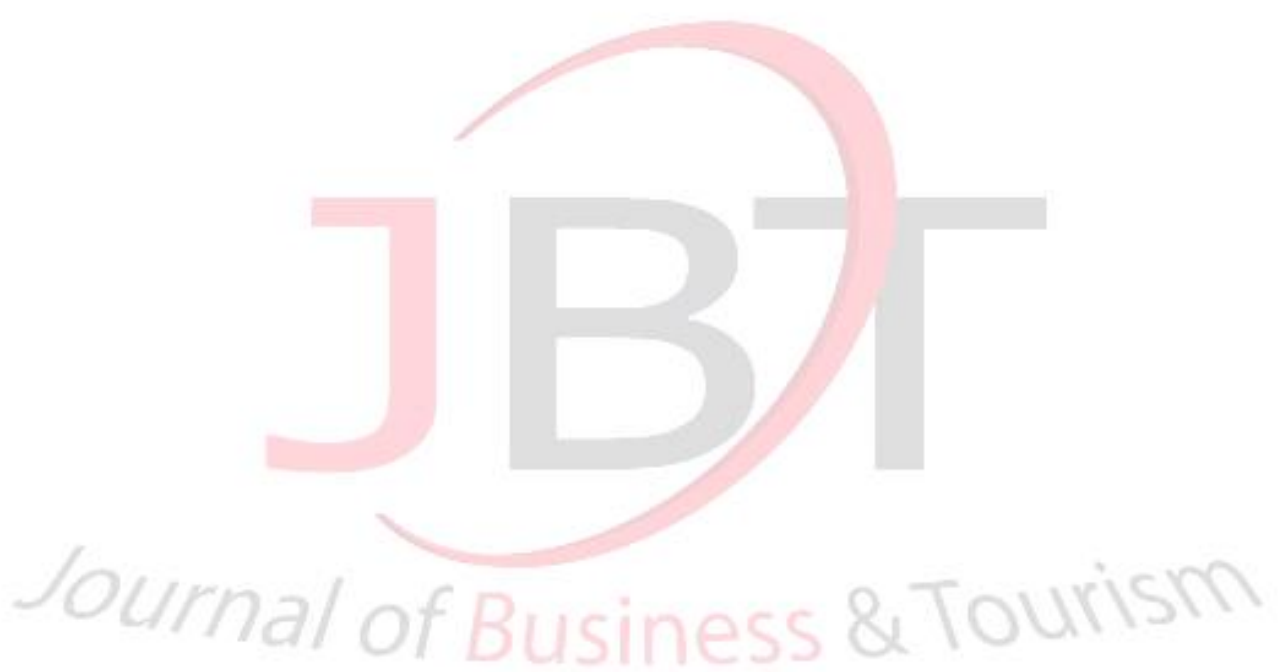


Table 1: Co-linearity statistics and correlation matrix of independent variables

\begin{tabular}{|c|c|c|c|c|c|c|c|c|c|c|}
\hline Variable Label & Tolerance & VIF & 1 & 2 & 3 & 4 & 5 & 6 & 7 & 8 \\
\hline 1-Autocratic & .985 & 1.015 & 1 & & & & & & & \\
\hline 2-Democratic & .980 & 1.021 & .012 & 1 & & & & & & \\
\hline 3-Transformational & .992 & 1.062 & .023 & $.230 *$ & 1 & & & & & \\
\hline 4-Charismatic & .995 & 1.005 & .007 & $.142 *$ & $.142 *$ & 1 & & & & \\
\hline 5-Quantity & .944 & 1.028 & $.234 * *$ & $.221 * *$ & .212 & .102 & 1 & & & \\
\hline 6-Quality & .936 & 1.287 & $.117 *$ & $.310 * * *$ & .142 & $.218^{*}$ & $.321 * *$ & 1 & & \\
\hline 7-Willingness & .914 & 1.293 & .101 & $.201 *$ & $.324 * *$ & $.341 * * *$ & $.241^{*}$ & $.289 *$ & 1 & \\
\hline 8-Inspiration & .911 & 1.052 & .025 & $.310 * *$ & $.251 *$ & $.351 * *$ & $.147 *$ & $.267 *$ & $.384 * * *$ & 1 \\
\hline
\end{tabular}

* Significant at the 10 percent level; **significant at the 5 percent level; ***significant at the 1 percent level (two tailed) 
Table-2: Regression results for four selected leadership styles

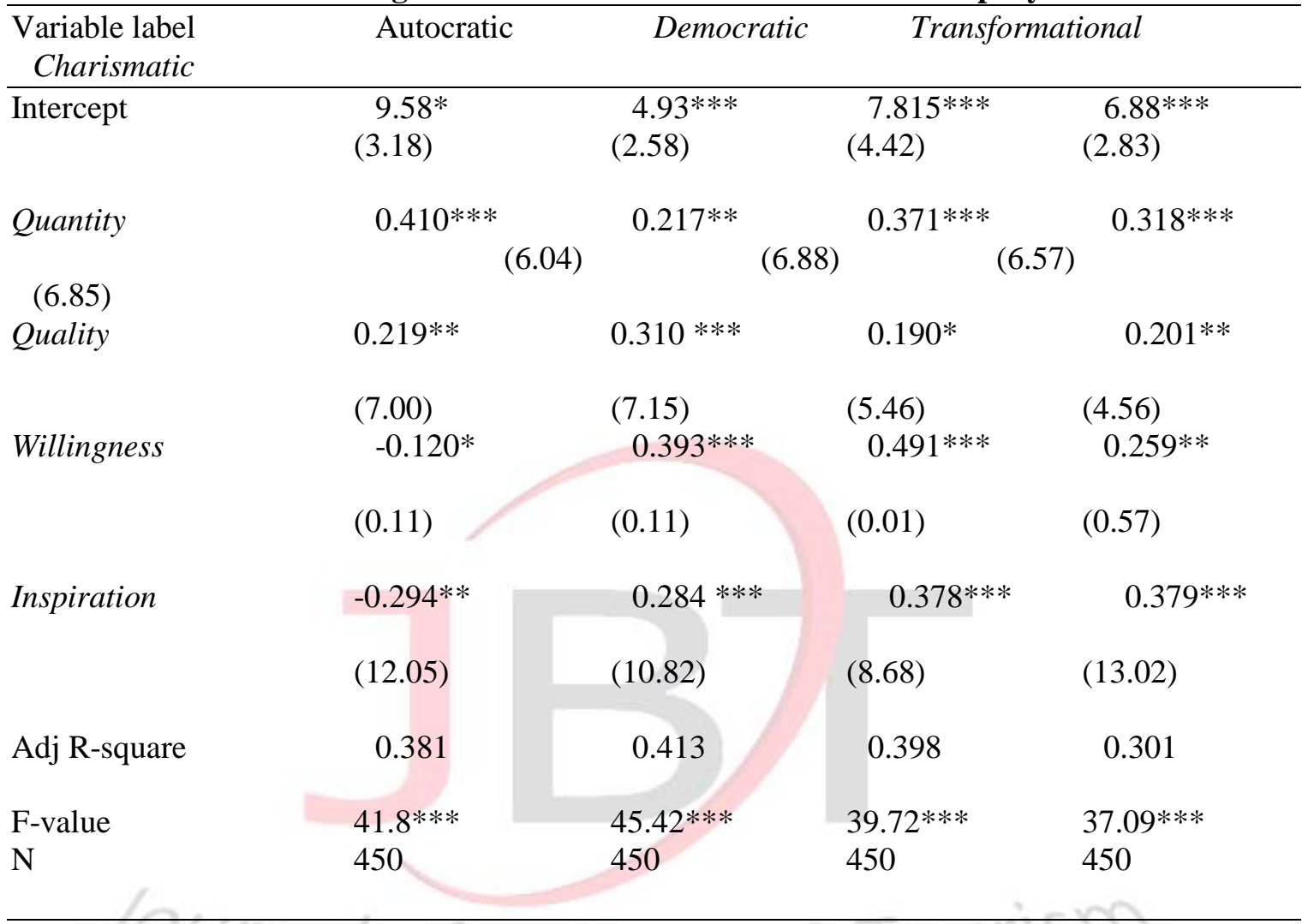

* significant at the 10 percent level; **significant at the 5 percent level; ***significant at the 1 percent level

Note: numbers in parentheses are $t$-statistics computed on the bases of robust standard errors ** The sample consists of 450 observations from 90 leaders and 5 followers of each leader

\section{Empirical analysis}

Table 1 shows the colorations and co-linearity statistics for independent and dependent variables. Transformational and democratic styles of leadership share several characteristics. Same is the case with transformational and charismatic styles. Not surprisingly, it is obvious that leadership styles are not completely exclusive of each other. Tolerance level and co-linearity statistics provide positive indication to use the independent variables in a regression. Four different regressions were used for four leadership styles. Table 2 represent the regression analyses. These results are also shown separately in figure 2 and 3 to see results in the mirror of proposed model. Results are discussed in detail in the coming section. 
Figur-2: Results

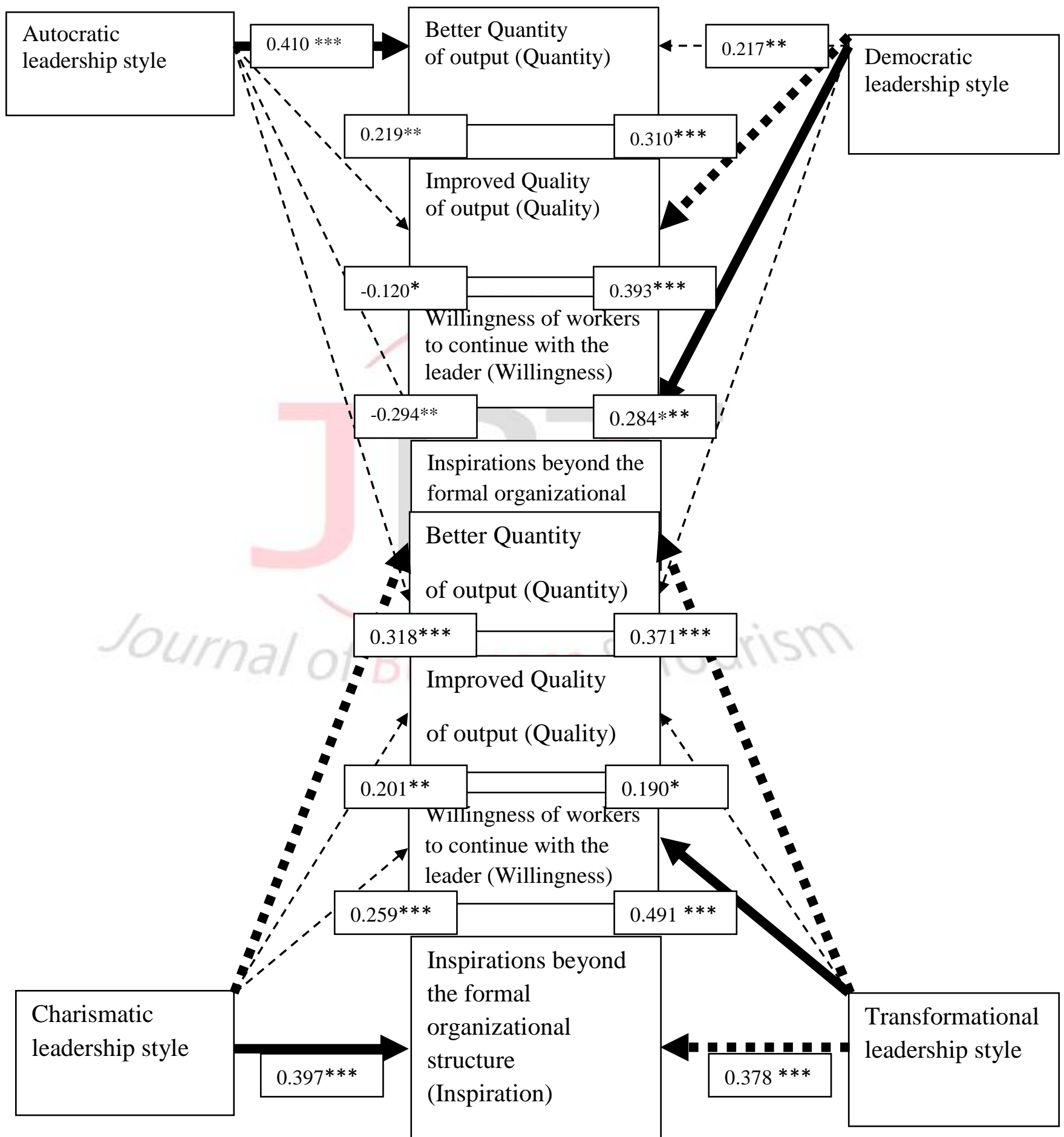




\section{Results and findings}

Results of data analyses are presented in the figure -2 and -3 . Figure -2 presents the results of Autocratic and Democratic leadership styles while figure -3 exhibits the findings for participative and Charismatic leadership styles.

Autocratic leadership style shows better results in terms of quantity of output. The result follows the hypothesized model. When companies look for cost containment and more production the control and monitoring function plays an important role. The autocratic leadership style also present positive association with improvement in quality of output. This is explainable with the preposition that close monitoring and control in small structure is helpful get improve both quality and quantity. However, this leadership style shows negative association both with the willingness of followers to continue and aspirations of followers beyond the organizational structure. These results presenting the negative sides of this leadership style are worth noticing. The analyses indicate strong control and monitoring can help to produce better quantity and also be quantity somehow but willingness and cooperation of followers is seriously damaged in this style. It is also plausible to conclude that on the face of high turnover, positive effects in quantity and apparent quantity will not be sustainable for long-term. One can expect a sudden fall in these measure, especially in quality, once the control is loosen, even for a short time.

Democratic leadership style shows strong association with the quality of output and willingness of followers to continue with the leader. This is in line with the hypothesized model. With an approach of participation and involvement the followers are self-motivated to produce better quality and this behavior is expected to continue without external influence of control. A low turnover and better employee satisfaction make the gains more sustainable in case of democratic leadership style. Unlike autocratic leadership style the results of democratic leadership style does not show any dark side and show positive association with quantity of output and inspiration of followers beyond the organizational structure.

As hypothesized charismatic leadership style shows better results for inspiration of workers beyond the organizational structure. The second stronger association is with the quantity of output. The results are understandable as enthusiasm is the most important upshot of this leadership style. This characteristic of charismatic leadership style make employees think leaders as an ideal to follow through thick and thin circumstances. The power of this style lies with the personality of leader rather than his situation or position. Thus, followers are expected to go for extraordinary efforts with enthusiasm and emotions to produce more in terms of quantity. The other two measures also show positive results for charismatic leadership style.

Finally participative leadership style shows positive results for the willingness of workers to continue with the leader. Additionally, this style also yields improvements in terms of inspiration of workers beyond the organizational structure. Hence, it is recommendable to use this style for low turnover, and motivate employees for challenging targets that need extraordinary efforts with long-term focus. Both charismatic and transformational leadership styles utilize strong feelings and excitement to boost the followers' efforts. In this sense, it is not surprising to get better quantity of output as an important outcome of both charismatic and participative leadership styles. 


\section{Conclusions}

This study examines the effectiveness of for representative leadership styles derived from different theories on leadership. The difficulty of measuring the effectiveness of leader and/or leadership style has been debated a lot in the previous literature (Avolio et al., 2004; Yukl, 2006). This study uses four measures of objective directions to judge the effectiveness of four different leadership styles in these directions. The analyses recommend that different leadership styles may be usable when requirements of SMEs differ in terms of four selected objective directions i. e., better quantity of out, improvement in quality of output, willingness of followers to continue and inspiration of followers beyond the organizational structure. Autocratic leadership style stands different from other three styles as it produces negative results in two directions presenting the negative side of this style. Other three leadership styles show different levels of effectiveness however do not show negative effects.

The findings explain that outcomes better quantity and quality are attainable with autocratic leadership style with negative effect on turnover and enthusiasm. Democratic leadership style is better usable for low turnover and better quality with no negative effects on quantity and enthusiasm. Charismatic leadership style and transformational leadership styles are most powerful when firm needs to motivate employees for a special assignment which demands extraordinary efforts with enthusiasm and excitement. Though quality comes as a priority after the better quantity, the analyses do not show any negative association as such.

\section{Limitations}

This study is focused on four selected leadership styles and four selected outcomes. Findings may not be generalized when other leadership styles and outcomes are in focus. Leadership is most researched area and defining leadership styles with mutually exclusive definitions is a challenge where margin of improvements is always present. Empirical part of this study uses the data of leaders and followers in SMEs operating in Pakistan. The results may need consideration of culture and economic circumstances before generalization for other economies.

\section{References}

Avolio, B. J., Zhu, W., Koh, W., and Bhatia, P. (2004). Transformational leadership and organizational commitment: mediating role of psychological empowerment and moderating role of structural distance. Journal of Organizational Behavior.

Baloch, Q. B. (2007). Managing Human Resource: Is There a Lesson for Pakistan in the Japanese Management Style. Journal of Managerial Sciences, 1(1), 1-25.

Baloch, Q. B., Ali, N., \& Zaman, G. (2014). Measuring employees commitment as outcome of transformational and transactional leadership styles: an empirical study. Abasyn Journal of Social Sciences, 3(2), 208-214.

Baloch, Q. B., \& Inam, M. (2007). Strategic thinking: Catalyst to competitive advantage. Journal of Managerial Sciences, 1(2), 1-26.

Bass B, and Bass R. (2008). The Bass handbook of leadership: Theory, research, and managerial applications. New York, NJ: Free Press.

Bass B. M. (1990). Bass and Stogdill's handbook of leadership (3 ed.). New York, NY: Free Press.

Bass, B. M. (1999). On the taming of charisma: a reply to Janice Beyer. Leadership Quarterly, 10, 541-553. 
Bhide, A. (1994). How Entrepreneurs Craft Strategies that Work, Harvard Business Review (March- April), 150-161.

Bird, B. (1992). The operation of intentions in time: The emergence of the new venture. Entrepreneurship Theory and Practice, 17: 11-20.

Blake, R., Mouton, J. S., (1964). The managerial grid. Houston, TX: Gulf.

Block, J. (1995). A contrarian view of the five-factor approach to personality description, Psychological Bulletin, 117, 187-215.

Buckley, P. J., (1989). Foreign Direct Investment by Small and Medium Sized Enterprises: The Theoretical Background, Small Business Economics 1(2), 89-100.

Burke, C. S., Stagl, K. C., Klein, C., Goodwin G. F., Salas, E., and Halpin, S. A., (2006). What types of leadership behaviors are functional in teams? A meta-analysis, Leadership Quarterly, 17, 288-307.

Burns, J. M. G., (1978). Leadership, New York: Harper \& Row.

Cogliser, C. C., and Schriesheim, C. A. (2000). Exploring Work Unit Context and LeaderMember exchange: A Multi-Level Perspective. Journal of Organizational Behavior , 487511.

Conger, J. A. (1991). Inspirin g others: the language of leadership. Academy of Management Executive, 5(1): 31-45.

Conger, J. A. and Kanungo, R.N. (1987). Toward a behavioral theory of charismatic leadership in organizational settings. Academy of Management Review, 12, 637-647.

Conger, J.A. and Kanungo, R.N. (1994). Charismatic leadership in organizations: perceived behavioral attributes and their measurement. Joumal of organizational behavior, 15 .

Conger, J. A., Kanungo, R. N., and Menon, S. T. (2000). Charismatic leadership and follower effects. Journal of Organizational Behavior.

Cannella, A. A., Jr., and Monroe, M. J. (1997). Contrasting perspectives on strategic leaders: Toward a more realistic view of top managers. Journal of Management, 23, 213-238.

Cook, K. J., (1992). AMA Complete Guide to Small Business Marketing, Lincolnwood: TC Business Books.

Carpenter, M. A., and Fredrickson, J. W. (2001). Top management teams, global strategic posture, and the moderating role of uncertainty, Academy of Management Journal, 44, 533-545.

Cowley, W. H. (1931). The traits of face-to-face leaders. The Journal of Abnormal and Social Psychology, 26(3), 304-313.

Davis, C. D., Gerald E. H. and Raymond W. L. (1985). The Marketing/Small Enterprise Paradox: A Research Agenda, International Small Business Journal 3(3), 31-41.

Day, D. V., and Lord, R. G. (1988). Executive leadership and organizational performance: suggestions for a new theory and methodology. Journal of Management, 14(3), 453-464.

Eden, L., Edward, Le., and Richard, J. M. (1997). The Production, Transfer and Spillover of Technology: Comparing Large and Small Multinationals as Technology Producers, Small Business Economics 9(1), 53-66.

Eggers, J., and Smilor, R.W. (1996). Leadership skills of entrepreneurs: Resolving paradoxes and enhancing the practices of leadership growth, In Leadership and entrepreneurship,

Fiedler, F. E. (1967). A theory of leadership effectiveness. New York: McGraw-Hill Education. 
Fiedler, F. E. (1970). Leadership experience and leader performance: Another hypothesis shot to hell. Organizational Behavior and Human Performance, 5, 1-14.

Ghemawat, P., (1991). Market Incumbency and Technological Inertia, Marketing Science 10(2), 161-171.

Hemphill, J. K. and Coons, A.E. (1957). Development of the leader behavior description questionnaire. In Stogdill RM, Coons AE (Eds.), Leader behavior: Its description and measurement, 6-38. Columbus, $\mathrm{OH}$ : Ohio state University.

Herbert, S., (1896). The Study of Sociology, New York D. Appleton and Company.

House, R. J., and Howell, J. M. (1992). Personality and charismatic leadership. Leadership Quarterly, 3: 81-108.

House, Robert J. (1977). A 1976 theory of charismatic Leadership. In J.G. Hunt and L.L. Larson (eds.), Leadership: The cutting edge. Carbondale, I11: Southern Illinois University Press.

Hunter, S.T., Bedell-Avers, K.E. and Mumford. M.D. (2007). The typical leadership study: Assumptions, implication and potential remedies. Leadership Quarterly 18, no. 5: 43546.

Isenberg, D. J. (1987). The tactics of strategic opportunism. Harvard Business Review, MarchApril: 92-97.

Jenkins, W. O. (1947). A review of leadership studies with particular reference to military problems. Psychological Bulletin, 44, 54-79.

Judge, T. A., and Bono, J. E. (2000). Five-factor model of personality and transformational leadership. Journal of Applied Psychology, 85, 751-765.

Judge, T. A., Higgins, C. A., Thoresen, C. J., and Barrick, M. R. (1999). The big five personality traits, general mental ability, and career success across the life span.Personnel Psychology, 52, 621-652.

Judge, T. A., Jackson, C. L., Shaw, J. C., Scott, B.A. and Rich, B.L. (2007). Self-efficacy and work related performance: The integral role of individual differences. Journal of Applied Psychology, 92, 107-127.

Judge, T. A. and Piccolo, R.F. (2004). Transformational and transactional leadership: A meta analytic test of their relative validity. Journal of Applied Psychology, 89, 755-768.

Kaiser, R. B., Hogan, R. and Craig, S. B. (2008). Leadership and the fate of organizations. American Psychologist, 63, 96-110.

Kao, Raymond W. Y. (1981). Small Business Management: A Strategic Emphasis, Toronto: Holt, Rinehart \& Winsto.

Khai S. L., Guan H. L. and Soo J. T. (1999). Dealing with Resource Disadvantage: Generic Strategies for SMEs, Small Business Economics, Vol. 12, No. 4 (Jun., 1999), pp. 299311.

Kickul, J., Neuman, G. (2000). Emergent leadership behaviors: The function of personality and cognitive ability in determining teamwork performance and KSAs. Journal of Business and Psychology, 15, 27-51.

Kinder, Donald R., Mark D. Peters, Robert P. Abelson, and Susan T. Fiske. (1980). Presidential Prototypes, Political Behavior 2: 315-337.

Kirkpatrick, S. A., and Locke, E. A. (1991). Leadership: Do traits really matter? Academy of Management Executive, 5, 48-60. 
Leanne, A., Robert, P. and Linda, R. (1991) "Personal Qualities of Charismatic Leaders", Leadership \& Organization Development Journal, Vol. 12 Iss: 2, pp.7 - 10.

Lefebvre, L. A. and Lefebvre, E. (1993) Competitive Positioning and Innovative Efforts in SMEs, Small Business Economics, Vol. 5, No. 4 (Dec., 1993), pp. 297-305.

Lefebvre, L. A. and Lefebvre, E. and Colin, D. (1991). Process Innovation, Productivity and Competitiveness in Smaller Manufacturing Firms," Canadian Journal of Administrative Sciences 8(1), 19-28.

Mann, R. D. (1959). A review of the relationships between personality and performance in small groups, Psychological Bulletin, 56, 241-270.

Marcus, G. E., Russell, N. R. and Michael B. Mac. (2000). Affective Intelligence and Political Judgment. Chicago: University of Chicago Press.

McGregor, D. (1960) The Human Side of Enterprise New York McGraw-Hill.

Meredith, J. (1987). The Strategic Advantages of New Manufacturing Technologies for Small Firms, Strategic Management Journal 8, 249-258.

Mintzberg, Henry (1979). The structuring of organizations: A synthesis of the research renticeHall (Englewood Cliffs, N.J.).

Moore, C. W. and Justin G. L. (1987). Small Business Management (7/e), Cincinnati: SouthWestern Publishing Company.

Mumford, T.V., Campion, M. A. and Morgeson, F. P. (2007). The leadership skills strataplex: Leadership skill requirements across organizational levels. Leadership Quarterly, 18, 154-166.

Newman, J. C. (1993). Opportunity Knocks, and Leaders Answer, Directors \& Boards 32, 48.

Pearce, C. L., and Jr., H. P. (2002). Vertical Versus Shared Leadership as Predictors of the effectiveness of Change Management Teams: An Examination of Aversive, Directive, Transactional, Transformational, and Empowering Leader Behaviors. Group Dynamics: Theory, Research, and Practice.

Porter, Michael E. (1980). Competitive Advantage: Creating and Sustaining Superior Performance, New York: Free Press.

Rahn, W. M. (2000). Affect as Information: The Role of Public Mood in Political Reasoning, In Elements of Reason, eds. Arthur Lupia, Matthew D. McCubbins, and Samuel L. Popkin. Cambridge: Cambridge University Press, 130-151.

Santarelli, E. and Sterlacchini A. (1990). Innovation, Formal vs. Informal R\&D and Firm Size: Some Evidence from Italian Manufacturing Firms, Small Business Economics 2,223-228.

Scarborough, N. M. and Thomas, W. Z. (1991). Effective Small Business Management (3/e), Columbus: Merrill Publishing Company.

Shah, S. N. U., Jan, S., \& Baloch, Q. B. (2018). Role of service quality and customer satisfaction in firm's performance: Evidence from Pakistan hotel industry. Pakistan Journal of Commerce and Social Sciences (PJCSS), 12(1), 167-182.

Stewart, J-A. (2009). Evaluation of an action learning programme for leadership development of SME leaders in the UK. Action Learning: Research and Practice 6, no. 2: 131-48.

Stogdill, R. M. (1948). Personal factors associated with leadership: A survey of the literature. Journal of Psychology, 25, 35-71. 
Stogdill RM. (1963). Manual for the leader behavior description questionnaire: Form XII. Columbus, OH: Ohio State University Bureau of Business Research, College of Commerce and Administration.

Sullivan, J., Aldrich, J., Borgida, E. and Rahn, W. (1990). Candidate appraisal and human nature: Man and Superman in the 1984 election. Political Psychology 11: 459-84.

Susan, M. J. and Fred L. (2006). Entrepreneurs as authentic leaders: impact on employees' attitudes, Emerald 27, (2006).

Taco, C. R. and Someren (1995). Sustainable Develop- ment and the Firm Organisational Innovations and Environmental Strategy, Business Strategy and the Environment 4, 23 33.

Tarkenton, F. and Joesph H. B. (1991), The Competitive edge: Essential Business Skills for Entrepreneurs, New York: Plume.

Thompson Jr. A.A and Strickland J.A (1996); Strategic Management - Concepts and Cases, Irwin.

Tichy, N. M., \& Devanna, M. A. (1986). The Transformational Leader. New York: Wiley.

Vecchio, R.P. (2003). Entrepreneurship and leadership: Common trends and common threads. Human Resources Management Review 13: 303-27.

Weinrauch, D. J., Mann, O. K., Robinson, P. A. and Julia, P. (1991). Dealing with Limited Financial Resources: A Marketing Challenge for Small Business, Journal of Small Business Management 29(4), 44-54.

Yukl, G. (2006). Leadership in Organizations (6 ed.). Upper Saddle River, New Jersey: Pearson Prentice Hall.

Yukl, G. (2008). How Leaders Influence Organizational Effectiveness. Leadership Quarterly, 19, 708-722. 